\title{
Ozônio como coadjuvante na terapia periodontal cirúrgica e não cirúrgica: revisão
} integrativa da literatura

\author{
Ozone as adjuvant in surgical and non-surgical periodontal therapy: an integrative review \\ El ozono como complemento de la terapia periodontal quirúrgica y no quirúrgica: revisión \\ integradora de la literatura
}

Recebido: 09/10/2021 | Revisado: 15/10/2021 | Aceito: 16/10/2021 | Publicado: 18/10/2021

\author{
Anísio Rodiney Souza Júnior \\ ORCID: https://orcid.org/0000-0002-3750-6182 \\ Centro Universitário de Patos de Minas, Brasil \\ E-mail: anisiorsj@unipam.edu.br \\ Carolina Silva Pereira \\ ORCID: https://orcid.org/0000-0003-2020-3932 \\ Centro Universitário de Patos de Minas, Brasil \\ E-mail: carolinasp@unipam.edu.br \\ Gabriel Borges Di Paolo \\ ORCID: https://orcid.org/0000-0002-6019-0841 \\ Centro Universitário de Patos de Minas, Brasil \\ E-mail: gabrielborgesdipaolo@unipam.edu.br \\ Fabrício Campos Machado \\ ORCID: https://orcid.org/0000-0003-4603-8795 \\ Centro Universitário de Patos de Minas, Brasil \\ E-mail: fabriciocampos@unipam.edu.br \\ Thiago de Amorim Carvalho \\ ORCID: https://orcid.org/0000-0003-1153-0931 \\ Centro Universitário de Patos de Minas, Brasil \\ E-mail: thiagocarvalho@unipam.edu.br
}

\begin{abstract}
Resumo
Dada a complexidade da etiopatogenia das doenças que acometem o periodonto, vários mecanismos de suporte à terapia periodontal convencional, baseada em etapas não cirúrgicas e cirúrgicas têm sido estudados na literatura entre eles, o ozônio em seus diversos veículos e com diversas finalidades. O objetivo deste estudo foi descrever as aplicações da ozonioterapia em Periodontia, nos âmbitos da terapia cirúrgica e não cirúrgica sob a óptica dos efeitos moleculares, celulares e teciduais focados no processo de reparo. Foi realizada uma revisão integrativa da literatura com busca nas bases de dados Pubmed/MEDLINE e SciELO com as chaves de busca, ozone, periodontal disease e periodontal surgery associadas por meio do operador booleano and. Após a aplicação dos critérios de elegibilidade elencados pela estratégia PRISMA-ScR, 15 artigos foram selecionados para a análise qualitativa visando a resposta da seguinte pergunta do estudo elaborada pela estratégia PICO: "Quais as vantagens da ozonioterapia na periodontia do ponto de vista microbiológico, celular e do reparo tecidual?”. Percebe-se que o ozônio é um bom coadjuvante à terapia periodontal convencional, por seus efeitos hemostáticos, angiogênicos, analgésicos, anti-hipóxicos e antimicrobianos, além de impactos sobre as vias moleculares de sinalização da resposta inflamatória, embora mais estudos sejam necessários para que protocolos de sua aplicação possam ser padronizados baseado na prática clínica baseada em evidência científica, haja vista o potencial de melhora no reparo tecidual e consequentemente no tempo de recuperação cirúrgica periodontal o que se desdobra para a qualidade de vida de pacientes acometidos por periodontite.
\end{abstract}

Palavras-chave: Ozônio; Periodontia; Odontologia.

\begin{abstract}
Given the complexity of the etiopathogenesis of the diseases that affect the periodontium, several mechanisms to support conventional periodontal therapy, based on non-surgical and surgical steps have been studied in the literature, including ozone in its various vehicles and with various purposes. The aim of this study was to describe the applications of ozone therapy in Periodontology, in the areas of surgical and non-surgical therapy from the viewpoint of molecular, cellular and tissue effects focused on the repair process. An integrative literature review was conducted using the Pubmed/MEDLINE and SciELO databases with the search terms ozone, periodontal disease and periodontal surgery associated with the Boolean operator and. After applying the eligibility criteria listed by the PRISMA-ScR strategy, 15 articles were selected for qualitative analysis in order to answer the following study question, developed by the PICO strategy: "What are the advantages of ozone therapy in periodontics from the microbiological, cellular
\end{abstract}


and tissue repair points of view? It is perceived that ozone is a good adjunct to conventional periodontal therapy, due to its hemostatic, angiogenic, analgesic, anti-hypoxic and antimicrobial effects, in addition to impacts on the molecular signaling pathways of the inflammatory response, Although further studies are needed so that protocols for its application can be standardized based on clinical practice based on scientific evidence, given the potential for improvement in tissue repair and consequently in periodontal surgical recovery time, which unfolds to the quality of life of patients affected by periodontitis.

Keywords: Ozone; Peridontics; Dentistry.

\begin{abstract}
Resumen
Dada la complejidad de la etiopatogenia de las enfermedades que afectan al periodonto, se han estudiado en la literatura varios mecanismos de apoyo a la terapia periodontal convencional, basados en pasos no quirúrgicos y quirúrgicos, entre ellos, el ozono en sus distintos vehículos y con diversos fines. El objetivo de este estudio fue describir las aplicaciones de la ozonoterapia en Periodoncia, en las áreas de terapia quirúrgica y no quirúrgica desde la perspectiva de los efectos moleculares, celulares y tisulares enfocados al proceso de reparación. Se realizó una revisión bibliográfica integradora mediante búsquedas en las bases de datos Pubmed/MEDLINE y SciELO utilizando las palabras clave ozono, enfermedad periodontal y cirugía periodontal asociadas al operador booleano y. Tras aplicar los criterios de elegibilidad enumerados por la estrategia PRISMA-ScR, se seleccionaron 15 artículos para su análisis cualitativo con el fin de responder a la siguiente pregunta de estudio, formulada mediante la estrategia PICO: "¿Cuáles son las ventajas de la ozonoterapia en periodoncia desde el punto de vista microbiológico, celular y de reparación de los tejidos? Se considera que el ozono es un buen complemento de la terapia periodontal convencional, debido a sus efectos hemostáticos, angiogénicos, analgésicos, antihipóxicos y antimicrobianos, así como a su impacto en las vías de señalización molecular de la respuesta inflamatoria, Aunque se necesitan más estudios para poder estandarizar los protocolos de su aplicación en base a la práctica clínica basada en la evidencia científica, dado el potencial de mejora en la reparación de los tejidos y consecuentemente en el tiempo de recuperación quirúrgica periodontal que se despliega en la calidad de vida de los pacientes afectados por la periodontitis.
\end{abstract}

Palabras clave: Ozono; Periodoncia; Odontología.

\title{
1. Introdução
}

$\mathrm{O}$ ozônio $\left(\mathrm{O}_{3}\right)$ está presente em abundância no ar atmosférico. A função desse gás na atmosfera é a proteção dos organismos vivos contra os raios ultravioletas. É produzido naturalmente pela fotodissociação das moléculas de oxigênio $\left(\mathrm{O}_{2}\right)$ em átomos de oxigênio ativados, que a partir de então reagem com outras moléculas de oxigênio. Após a reação química de protonação, é gerado trióxido de oxigênio $\left(\mathrm{HO}_{3}\right)$, que por fim se decompõe no radical hidroxila $(\mathrm{OH})(\mathrm{Naik}$, Rajeshwari, Zohabhasan \& Bhatia, 2016).

Christian Friedrich identificou o ozônio pela primeira vez em 1840, a partir do odor percebido após eventos de descargas elétricas na atmosfera. A partir daí a gama de procedimentos a utilizarem o ozônio começou a se diversificar sendo utilizado para a desinfecção de salas de operação em 1856 e para desinfetar e curar feridas cirúrgicas dentárias em 1930 (Suh et al., 2019).

O uso do ozônio na Odontologia tem sido estudado e aumentado devido às suas propriedades antimicrobianas, curativas e biocompatibilidade. O ozônio tem sido avaliado para vários procedimentos como regenerações ósseas, remineralização de lesões brancas, tratamento endodôntico e periodontal, sensibilidade dentinária e controle da dor na ATM (Pietrocola et al., 2018).

A periodontite se apresenta como uma inflamação do tecido periodontal, em que ocorre perda de inserção clínica, perda óssea e sangramento espontâneo ou à sondagem (Moraschini et al., 2020). A doença periodontal é uma infecção multifatorial causada por microrganismos anaeróbicos gram-negativos que pode levar à destruição dos tecidos de suporte dentais. O tratamento é dividido entre a terapia não cirúrgica e cirúrgica, sendo o início, de forma não cirúrgica, realizando remoção mecânica de depósitos bacterianos supra gengivais e sub gengivais. A terapia cirúrgica é indicada para regiões de difícil acesso sobre a superfície radicular (Roman-Torres et al., 2018).

A terapia periodontal convencional tem por objetivo a redução da placa bacteriana e eliminação das bactérias que ocupam as bolsas periodontais, porém existem algumas dificuldades dessa terapia, como por exemplo, a profundidade de 
algumas bolsas e algumas áreas de mais difícil acesso na boca. A aplicação do ozônio torna-se mais factível, por ter mais fácil utilização e resolver as limitações da terapia convencional (Silva et al., 2020).

Várias vias sinalizadoras moleculares para a doença periodontal têm sido descritas na literatura, e uma das mais reconhecidas é a via do RANK-L. O RANK-L é um polipeptídeo que pode ser expresso ligado a membranas protéicas ou ainda em formas séricas. Essa citocina está fortemente associada à reabsorção óssea na patogenia da doença periodontal. Uma maior concentração de RANK-L parece estar associada a graus mais avançados de doença periodontal e o ozônio tem potencial de inibição dessa via de expressão gênica (Chen et al., 2014; Walsh et al., 2013; Tasdemir, Alkan \& Albairak, 2019).

O objetivo desse estudo foi descrever as aplicações da ozonioterapia em Periodontia, nos âmbitos da terapia cirúrgica e não cirúrgica sob a óptica dos efeitos moleculares, celulares e teciduais focados no processo de reparo.

\section{Metodologia}

Trata-se de uma revisão integrativa da literatura sobre o uso do ozônio como tratamento coadjuvante para a doença periodontal. Foi utilizada estratégia PICO, na qual para P (paciente ou grupo de estudo) foi atribuído o paciente com periodontite), para I (intervenção) foi atribuído o uso do ozônio, para C (controle) foi atribuído a terapia periodontal convencional e para $\mathrm{O}$ (desfecho) foram atribuídos a diminuição das bactérias e das respostas inflamatórias, aumento do processo de reparo, que culminaram com a elaboração da pergunta do estudo: "Quais as vantagens da ozonioterapia na periodontia do ponto de vista microbiológico, celular e do reparo tecidual?". As bases de dados utilizadas para a busca e seleção dos artigos foram (PubMed, Google Scholar, SciELO, Biblioteca Virtual em Saúde), utilizando os seguintes termos de busca ozone, periodontal disease, periodontal surgery, com o operador booleano and e os correspondentes em português ozônio, doença periodontal, cirurgia periodontal, com o operador booleano "e", bem como os cruzamentos: "ozone and periodontal disease", "ozone and periodontal surgery"; "ozônio e doença periodontal", "ozônio e cirurgia periodontal".

Os critérios de inclusão foram artigos nos idiomas português ou inglês, disponíveis na íntegra, com no máximo 10 anos de publicação, metanálises, revisões sistemáticas, ensaios clínicos randomizados e os critérios de exclusão aplicados foram artigos com mais de 10 anos de publicação, em idioma adverso ao estabelecido, estudos em que não se foi possível localizar o texto completo, também foram excluídos trabalhos da literatura cinzenta que incluem artigos não submetidos à revisão pelos pares, monografias, trabalhos de conclusão de curso, teses e dissertações. O fluxograma de seleção de artigos encontra-se apresentado na Figura 1. 
Figura 1 - Fluxograma do processo de seleção dos estudos primários adaptado do Preferred Reporting Items for Systematic review and Meta-Analyses (PRISMA-ScR).

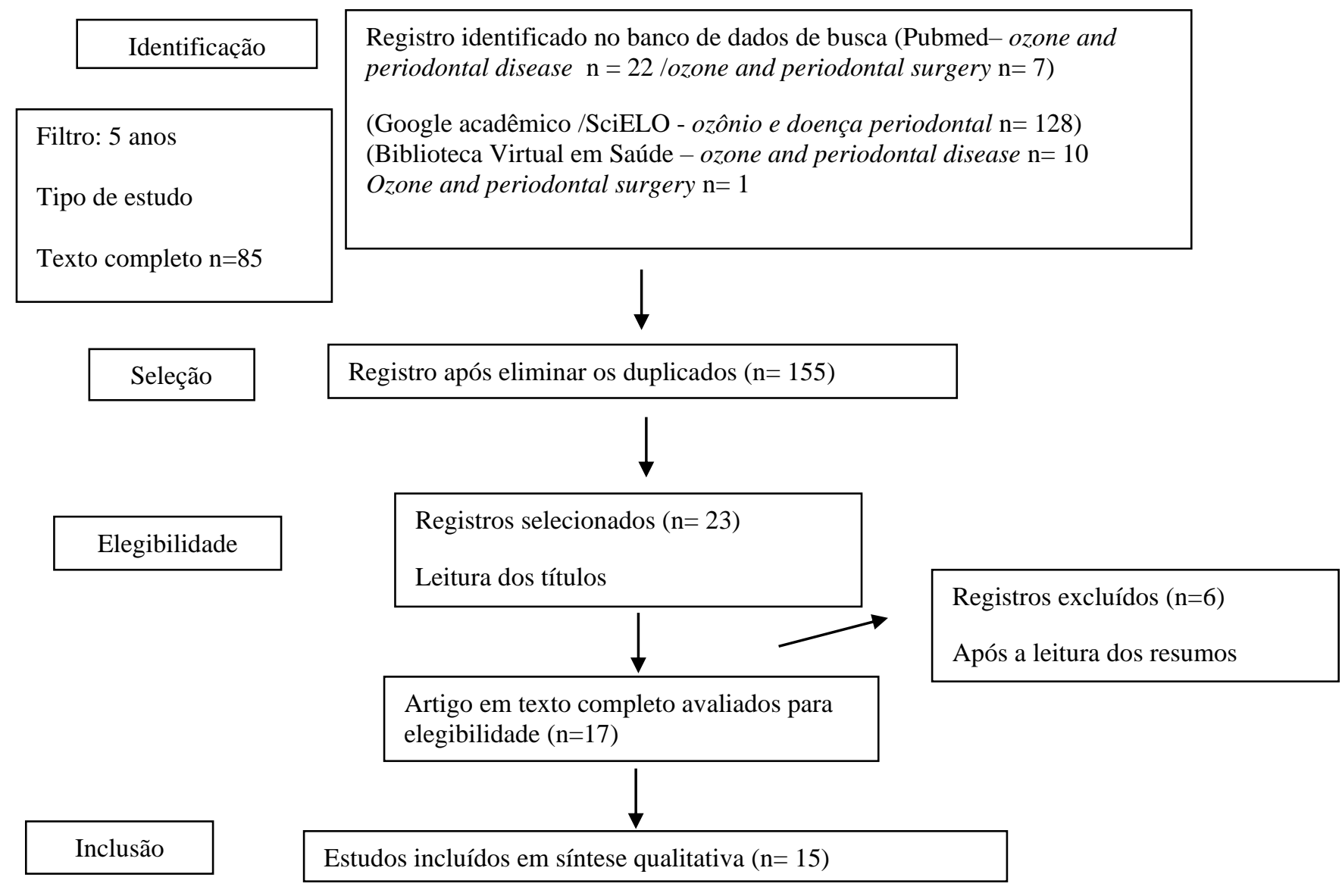

Fonte: Autores.

Os artigos foram inicialmente selecionados pelos termos de busca, seguido pela leitura de título e de resumos, para qual foi levada em consideração a resposta à pergunta do estudo, seguida da consonância com os desfechos esperados para este estudo. Após a aplicação dos critérios de elegibilidade e leitura completa dos trabalhos, 15 artigos foram selecionados.

\section{Resultados}

Após a aplicação dos critérios de elegibilidade foram selecionados 15 artigos para a análise qualitativa. O Quadro 1, apresenta a caracterização dos estudos conforme autor, ano de publicação, periódico, tipo de estudo, objetivo e principais resultados. 
Quadro 1 - Caracterização dos estudos selecionados após aplicação dos critérios de elegibilidade.

\begin{tabular}{|c|c|c|c|c|}
\hline Autor, ano & Periódico & Objetivo & Tipo de Estudo & Resultados principais \\
\hline $\begin{array}{l}\text { SAGLAM et al., } \\
2020\end{array}$ & $\begin{array}{l}\text { Journal of Applied } \\
\text { Oral Science }\end{array}$ & $\begin{array}{l}\text { Determinar o efeito sistêmico e } \\
\text { tópico do Ozônio no osso } \\
\text { alveolar. }\end{array}$ & $\begin{array}{l}\text { Pesquisa } \\
\text { exploratória. }\end{array}$ & $\begin{array}{l}\text { Ambas as aplicações de Ozônio } \\
\text { foram eficazes para a periodontite } \\
\text { experimental, sendo que a } \\
\text { aplicação sistêmica foi mais eficaz. }\end{array}$ \\
\hline $\begin{array}{l}\text { SILVA et al., } \\
2020\end{array}$ & $\begin{array}{l}\text { Research, Society and } \\
\text { Development }\end{array}$ & $\begin{array}{l}\text { Avaliar se a ozonioterapia é } \\
\text { eficaz no tratamento da peri- } \\
\text { implantite. }\end{array}$ & Revisão de escopo & $\begin{array}{l}\text { A terapia de ozônio, com suas } \\
\text { poderosas propriedades, tem } \\
\text { grande potencial no tratamento da } \\
\text { peri-implantite. }\end{array}$ \\
\hline $\begin{array}{l}\text { FERREIRA } \\
\text { FILHO et al., } \\
2020\end{array}$ & $\begin{array}{l}\text { Brazilian Journal of } \\
\text { Development }\end{array}$ & $\begin{array}{l}\text { Salientar o uso de óleo ozonizado } \\
\text { para a cicatrização de feridas } \\
\text { cirúrgicas, principalmente na } \\
\text { periodontia e implantodontia. }\end{array}$ & $\begin{array}{l}\text { Revisão } \\
\text { literatura }\end{array}$ & $\begin{array}{l}\text { Embora o ozônio traga benefícios, } \\
\text { devem ser realizados mais estudos } \\
\text { clínicos, para que seu uso seja mais } \\
\text { adequado. }\end{array}$ \\
\hline $\begin{array}{l}\text { MORASCHINI } \\
\text { et al., } 2020\end{array}$ & $\begin{array}{ll}\text { Clinical } & \text { Oral } \\
\text { Investigations } & \end{array}$ & $\begin{array}{l}\text { Avaliar o efeito da terapia com } \\
\text { ozônio de forma coadjuvante ao } \\
\text { tratamento periodontal não } \\
\text { cirúrgico. }\end{array}$ & $\begin{array}{l}\text { Revisão } \\
\text { sistemática } \\
\text { meta-análise }\end{array}$ & $\begin{array}{l}\text { Os resultados deste estudo não } \\
\text { suportam o uso do ozônio, porém } \\
\text { devido ao potencial de } \\
\text { heterogeneidade, tais resultados } \\
\text { não devem ser considerados } \\
\text { definitivos. }\end{array}$ \\
\hline $\begin{array}{l}\text { ALINCA et al., } \\
2020\end{array}$ & $\begin{array}{l}\text { Biotechnic \& } \\
\text { Histochemistry }\end{array}$ & $\begin{array}{l}\text { Avaliar efeitos do Ozônio e laser } \\
\text { na destruição óssea induzida por } \\
\text { doença periodontal. }\end{array}$ & $\begin{array}{l}\text { Pesquisa } \\
\text { Exploratória }\end{array}$ & $\begin{array}{l}\text { Tanto a terapia à laser quanto a } \\
\text { ozonioterapia trouxeram } \\
\text { benefícios, sendo que a primeira } \\
\text { trouxe melhores resultados. }\end{array}$ \\
\hline $\begin{array}{l}\text { NICOLINI et al., } \\
2020\end{array}$ & $\begin{array}{ll}\text { Clinical } & \text { Oral } \\
\text { Investigations } & \end{array}$ & $\begin{array}{l}\text { Avaliar o efeito que a água } \\
\text { ozonizada exerce na formação de } \\
\text { placa e inflamação gengival. }\end{array}$ & $\begin{array}{l}\text { Ensaio clínico } \\
\text { randomizado }\end{array}$ & $\begin{array}{l}\text { O resultado principal, não } \\
\text { apresentou diferença significativa } \\
\text { entre os grupos Teste e Controle. }\end{array}$ \\
\hline $\begin{array}{l}\text { TASDEMIR et } \\
\text { al., } 2016\end{array}$ & $\begin{array}{l}\text { Journal of } \\
\text { Periodontology }\end{array}$ & $\begin{array}{l}\text { Avaliar os benefícios da terapia } \\
\text { com ozônio durante o período de } \\
\text { cicatrização de enxertos gengivais } \\
\text { desepitelizados. }\end{array}$ & $\begin{array}{l}\text { Ensaio clínico } \\
\text { randomizado }\end{array}$ & $\begin{array}{l}\mathrm{O} \text { grupo tratado com ozônio } \\
\text { apresentou maior qualidade de } \\
\text { vida que o grupo controle. }\end{array}$ \\
\hline $\begin{array}{l}\text { MAKEEVA et } \\
\text { al., } 2020\end{array}$ & $\begin{array}{l}\text { Clinical, Cosmetic } \\
\text { and Investigational } \\
\text { Dentistry }\end{array}$ & $\begin{array}{l}\text { Avaliar se o uso do ozônio é } \\
\text { benéfico ou não para tratamento } \\
\text { de lesões endo-perio. }\end{array}$ & $\begin{array}{l}\text { Relato de caso } \\
\text { clínico e revisão } \\
\text { de literatura }\end{array}$ & $\begin{array}{l}\text { A ozonioterapia se mostrou } \\
\text { benéfica para tratamento de lesões } \\
\text { endo-perio com bolsas } \\
\text { periodontais estreitas em pacientes } \\
\text { com doença periodontal agressiva } \\
\text { e prognóstico ruim. }\end{array}$ \\
\hline $\begin{array}{l}\text { DENGIZEK et } \\
\text { al.,2018 }\end{array}$ & $\begin{array}{l}\text { Journal of Applied } \\
\text { Oral Sciences }\end{array}$ & $\begin{array}{l}\text { Avaliar os efeitos do ozônio } \\
\text { acompanhado de raspagem e } \\
\text { alisamento radicular em } \\
\text { tratamentos periodontais. }\end{array}$ & $\begin{array}{l}\text { Ensaio controlado } \\
\text { randomizado }\end{array}$ & $\begin{array}{l}\text { O ozônio gasoso junto da } \\
\text { raspagem radicular não apresentou } \\
\text { melhora significativa no no } \\
\text { prognóstico periodontal em relação } \\
\text { à raspagem radicular de forma } \\
\text { individual. }\end{array}$ \\
\hline $\begin{array}{l}\text { RAPONE et al., } \\
2020\end{array}$ & $\begin{array}{l}\text { International Journal } \\
\text { of Environmental } \\
\text { Research and Public } \\
\text { Health }\end{array}$ & $\begin{array}{l}\text { Avaliar o uso do tratamento } \\
\text { periodontal convencional em } \\
\text { conjunto com ozônio na redução } \\
\text { do nível de hemoglobina glicada } \\
\text { em diabéticos tipo } 2 \text {. }\end{array}$ & $\begin{array}{l}\text { Estudo clínico } \\
\text { randomizado }\end{array}$ & $\begin{array}{l}\text { A terapia com } \\
\text { benefícios emônio trouxe } \\
\text { tratamento } \\
\text { convencional. }\end{array}$ \\
\hline $\begin{array}{l}\text { ISLER et al., } \\
2018\end{array}$ & $\begin{array}{l}\text { Journal of Periodontal } \\
\text { and Implant Science }\end{array}$ & $\begin{array}{l}\text { Determinar o efeito da terapia de } \\
\text { ozônio gasoso adicional na } \\
\text { descontaminação de superfícies } \\
\text { dos implantes na terapia } \\
\text { regenerativa cirúrgica de Peri- } \\
\text { implantite. }\end{array}$ & $\begin{array}{l}\text { Pesquisa } \\
\text { exploratória }\end{array}$ & $\begin{array}{l}\text { A descontaminação da superfície } \\
\text { do implante com o uso de ozônio } \\
\text { manifestou clínica } \\
\text { radiograficamente considerável. }\end{array}$ \\
\hline $\begin{array}{l}\text { ALSHERIF et al., } \\
2020\end{array}$ & $\begin{array}{lr}\text { Journal of } \begin{array}{r}\text { Oral } \\
\text { Biology and } \\
\text { Craniofacial Research }\end{array}\end{array}$ & $\begin{array}{l}\text { Avaliar o poder de regeneração da } \\
\text { doença periodontal da fibrina rica } \\
\text { em plaquetas e do ozônio. }\end{array}$ & $\begin{array}{l}\text { Estudo clínico } \\
\text { randomizado }\end{array}$ & $\begin{array}{l}\text { Tanto o ozônio quanto a fibrina } \\
\text { rica em plaquetas podem melhorar } \\
\text { a cicatrização de defeitos } \\
\text { periodontais intraósseos. }\end{array}$ \\
\hline
\end{tabular}




\begin{tabular}{|l|l|l|l|l|}
\hline $\begin{array}{l}\text { TASDEMIR et } \\
\text { al., 2019 }\end{array}$ & $\begin{array}{l}\text { Oral Diseases } \\
\text { ozônio os relação aos parâmetros } \\
\text { clínicos e bioquímicos de } \\
\text { pacientes com periodontite } \\
\text { generalizada após terapia } \\
\text { periodontal não cirúrgica. }\end{array}$ & $\begin{array}{l}\text { Estudo clínico } \\
\text { randomizado }\end{array}$ & $\begin{array}{l}\text { A ozonioterapia não teve nenhum } \\
\text { resultado adicional nos parâmetros } \\
\text { periodontais. }\end{array}$ \\
\hline $\begin{array}{l}\text { LEEWANANTH } \\
\text { AWET et al., } \\
2019\end{array}$ & $\begin{array}{l}\text { Science of } \\
\text { technology and } \\
\text { advanced materials }\end{array}$ & $\begin{array}{l}\text { Examinar as respostas celulares } \\
\text { após tratamento com Ozônio } \\
\text { aquoso de bolha ultrafina. }\end{array}$ & $\begin{array}{l}\text { Estudo in vitro } \\
\text { numerosos genes envolvidos nas } \\
\text { respostas ao estresse oxidativo } \\
\text { regulados de forma positiva após o } \\
\text { tratamento, e também a atividade } \\
\text { bactericida, no tratamento da } \\
\text { periodontite. }\end{array}$ \\
\hline
\end{tabular}

Fonte: Autores.

Dos artigos lidos, um total de nove trazem alguns benefícios da terapia com ozônio, como por exemplo, diminuição de células positivas para RANKL e HIF-1- $\alpha$, melhor prognóstico em bolsas periodontais estreitas em pacientes com periodontite agressiva, eficácia na redução do estado inflamatório periodontal, descontaminação da superfície de implantes em casos de peri-implantite, melhora em relação à parâmetros histológicos associados a cura de defeitos periodontais intra-ósseos, auxilio na formação óssea alveolar, aumento da perfusão sanguínea, melhora na cicatrização, melhora na qualidade de vida e diminuição da dor pós operatória.

Em outros cinco estudos, a ozonioterapia não teve nenhum efeito adicional nos parâmetros periodontais ou obteve efeito quase nulo.

Apenas um estudo trouxe malefícios da terapia com ozônio, que caracteriza ausência de diferenças estatísticas entre os grupos de pesquisa, tanto em início de formação de placa quanto em volume de fluído gengival crevicular, revela também que a aplicação de água ozonizada não apresenta suporte para o tratamento de infecções orais e não pode modificar o fator causal dessas doenças, que é o biofilme. Além disso, neste trabalho, a terapia causou um número considerável de eventos adversos.

\section{Discussão}

A periodontite é uma inflamação crônica multifatorial causada por bactérias patogênicas e pela resposta do hospedeiro, que degrada os tecidos de suporte de dentes e osso, o que pode levar à perda do elemento dental (Alinca, Saglam, Celik, Hacisalihoglu \& Dogan, 2020). Os microrganismos representam um papel importante na patogênese e etiologia da doença. A resposta do hospedeiro protege o periodonto do ataque das bactérias, evita que os microrganismos patogênicos se espalhem pelo tecido, porém pode danificar as células do periodonto e do tecido conjuntivo, causando destruição no ligamento periodontal, osso alveolar e cemento (Saglam, Alinca, Celik, Hacisalihoglu \& Doglan, 2020).

Apesar de serem apresentadas várias modalidades de tratamento, a base do tratamento periodontal está na remoção mecânica de placa microbiana e cálculo e alisamento das raízes (Tasdemir et al; 2016). Tanto a terapia não cirúrgica quanto a terapia cirúrgica apresentam benefícios quando combinadas à terapia com ozônio, trazendo uma melhora na saúde periodontal e redução no risco de perda do dente (Dengizek et al., 2018).

A ozonioterapia pode ser utilizada na Odontologia nas formas gasosa e aquosa, podendo o ozônio ser dissolvido na água ou óleo. O gás ou óleo e água ozonizados podem ser aplicados em feridas cirúrgicas, áreas de infecção ou nos próprios sulcos. Como o ozônio é um gás instável, ele pode ser associado a um veículo aquoso para promover uma conversão mais rápida ou a um veículo viscoso para tornar a conversão mais lenta (Silva et al., 2021). Dentre as diferentes formas de apresentação e aplicação do ozônio, pode-se afirmar que o óleo apresenta vantagens em relação ao meio aquoso e gasoso 
quando se trata de maior tempo de contato com a superfície e possibilita um armazenamento por mais tempo sem que haja inativação (Ferreira Filho et al., 2020).

Atualmente, o ozônio tem sido utilizado na indústria alimentícia e na Odontologia como um antisséptico (Leewananthawet et al., 2019). Ele tem um potencial anti-hipóxico, analgésico, é um modulador imunológico (Saglam et al., 2020), além de apresentar um grande poder de oxidação e antimicrobiano por isso, pode ser utilizado como um desinfetante em aplicações odontológicas. Dos estudos selecionados Rapone et al. (2020), Alsherif, Eltokhey e Taiema (2020), Leewananthawet et al. (2019) e Isler et al. (2018) relatam uma forte atividade antimicrobiana do ozônio contra microrganismos periodontais patogênicos anaeróbios, portanto pode ser uma ótima ferramenta complementar à terapia periodontal não cirúrgica em pacientes com periodontite crônica. Por conta de suas propriedades, o ozônio fez muitas áreas da Odontologia começarem a explorar suas vantagens, principalmente no que diz respeito ao seu potencial antimicrobiano (Uslu \& Akgul, 2020), inclusive atuando sobre Candida albicans, se tornando grande complemento na terapia periodontal (Alsherif et al., 2020).

O gás permite que o oxigênio possa se mover para dentro dos tecidos com mais facilidade, aumentando assim a quantidade de 2,3- difosfoglicerato e eritrócitos que também são responsáveis por um aumento nos radicais livres de oxigênio levando a uma mudança na atividade do sistema imunológico e nos níveis de enzimas antioxidantes (Saglam et al.,2020), além de benéficos nas células e componentes do sistema imunológico humoral, estimulando a proliferação de células imunocompetentes e síntese de imunoglobulinas. (Dengizek et al., 2018). A terapia com ozônio é capaz de melhorar a oxigenação do tecido afetado e de reduzir o processo inflamatório, portanto, age de forma positiva em algumas doenças infecciosas (Saglam et al., 2020). Além disso, a ozonioterapia pode promover hemostasia, inibir proliferação bacteriana, aumentar liberação de fatores de crescimento e regular positivamente as enzimas antioxidantes celulares (Isler et al., 2018).

Além desses efeitos, o uso do ozônio também aumenta a sensibilidade dos microrganismos à fagocitose e faz ativação de macrófagos e as células do corpo produzem certas citocinas como resposta a ativação causada por esse gás. Por fim, desencadeia a síntese de várias substâncias biologicamente ativas que reduzem inflamação e promovem cicatrização de feridas, como interleucinas, leucotrienos e prostaglandinas (Dengizek et al., 2018).

O ozônio danifica o sistema bacteriano, a nível de parede celular e membrana citoplasmática, causando um distúrbio funcional com degradação de proteínas e por fim, destruindo-as. Ele é biocompatível com os tecidos gengivais, suas propriedades antimicrobianas podem ser úteis para controle químico de biofilme e sua ação inflamatória pode modular a doença periodontal (Nicolini et al., 2020). Entretanto, nos estudos realizados por Nicolini et al. (2020), Dengizek et al. (2018), Tasdemir, Oskaybas, Alkan e Cakmak (2019) e Morashini et al. (2020) o ozônio não apresentou diferença entre grupos de teste e controle, nem melhora significativa no prognóstico periodontal em relação a raspagem radicular sozinha. Quando utilizado no tratamento de pacientes com patologia periodontal pode ter um efeito benéfico, estudos recentes de Alinca et al. (2020), Alsherif et al. (2020), Isler et al. (2018), Leewananthaw et al. (2019), Makeeva, Daurova, Byakova e Turkina (2020), Rapone et al. (2020), Saglam et al. (2020), Silva et al. (2020), Tasdemir, Alkan e Albayrak (2016) comprovam a boa atividade antimicrobiana e a biocompatibilidade com as células periodontais e fibroblastos gengivais, quando aplicada como coadjuvante à terapia periodontal convencional, a ozonioterapia melhora de forma significativa os parâmetros clínicos da doença periodontal (Makeeva et al., 2020).

Outra aplicação da terapia com ozônio é em relação a pacientes com periodontite agressiva cujos mecanismos imunológicos locais podem estar alterados. Nestes casos o ozônio ativa o metabolismo celular, melhora propriedades reológicas, aumenta as concentrações de ATP intracelular e citocinas importantes para cicatrização de feridas. A ozonioterapia também pode apresentar vantagens em casos onde existem bolsas periodontais em que a terapia não cirúrgica é de complicada realização pelo difícil acesso (Makeeva et al., 2020). Maiores perdas ósseas na doença periodontal, podem estar intimamente ligadas à via do RANK-L, que é responsável pela reabsorção óssea. A terapia com ozônio diminui a expressão de RANK-L, 
portanto, reduz a reabsorção óssea, sendo um tratamento importante para a melhora da cicatrização do osso alveolar (Alinca et al., 2020).

A terapia com ozônio exerce efeitos positivos nos parâmetros de perfusão sanguínea, hemostasia e por consequência, uma melhora na cicatrização dos tecidos periodontais. O aumento da vascularização devido ao processo de angiogênese restabelece a rede microvascular do tecido conjuntivo e fornece nutrientes e oxigênio para a região da ferida, fazendo com que se acelere o processo de cicatrização. Este resultado também é relacionado ao aumento da qualidade de vida e diminuição da dor pós-operatória (Tasdemir et al., 2016). Outra questão envolvida pelo tratamento com ozônio está relacionada à estimulação de produção de óxido nítrico, que exerce efeitos locais e sistêmicos, incluindo vasodilatação (Rapone et al., 2020).

Em estudos realizados por Rapone et al. (2020), Makeeva et al. (2020), Saglam et al. (2020) e Silva et al. (2020) conclui-se que as aplicações de ozônio foram eficazes para a periodontite com a aplicação sistêmica sendo mais eficaz, com grande potencial para o tratamento da peri-implantite e lesões endo-perio com bolsas periodontais, conferindo maior qualidade de vida para os grupos tratados. Alinca et al. (2020) demostrou também que a terapia com ozônio e a terapia a laser trouxeram benefícios para o tratamento da destruição óssea, embora com os benefícios relatados, Ferreira Filho et al. (2020) e Moraschini et al. (2020) inferem que ainda são necessários mais estudos clínicos para suportarem, de fato, o uso do ozônio para tratamentos relacionados com a periodontite.

\section{Conclusão}

A partir da análise qualitativa dos estudos selecionados para este estudo, é possível concluir que a terapia com ozônio parece apresentar diversas vantagens, principalmente se usada como adjuvante à terapia periodontal convencional, que conforme os resultados encontrados na pesquisa, ainda se mostra indispensável no tratamento da doença periodontal. Os benefícios do ozônio identificados neste trabalho tais como o bom potencial antimicrobiano, biocompatibilidade com as células periodontais, redução de inflamação, hemostasia, inibição da proliferação bacteriana, melhor acesso em regiões de bolsas profundas, aumento da liberação de fator de crescimento, dentre outras vantagens, que podem culminar em melhor reparo tecidual, são relevantes e podem impactar diretamente no sucesso do tratamento periodontal, e consequentemente na melhoria da qualidade de vida das pessoas acometidas pela periodontite. Levando em consideração os benefícios que a terapia com ozônio pode trazer ao paciente em relação à melhor prognóstico no que concerne ao tratamento periodontal, mais estudos são necessários para que se possa instituir protocolos de aplicação de ozônio na terapia periodontal não cirúrgica e cirúrgica, pautados na prática da Odontologia Baseada em Evidência Científica.

\section{Referências}

Alinca, S. B., Saglam, E., Celik, T. Z., Hacisalihoglu, P., \& Dogan, M. A. (2020). Is low level laser therapy or ozone therapy more effective for bone healing? Understanding the mechanisms of HIF-1 $\alpha$, RANKL and OPG. Biotechnic Histochemistry, 95 (8), 597-604. https://doi.org/10.1080/10520295.2020.1743360

Alsherif, A. A., Eltokhey, H M., \& Taiema D. A. (2020). Platelet rich fibrin versus ozone gel for periodontal regeneration in induced rats' intrabony three-wall periodontal defects. Journal of Oral Biology and Craniofacial Research, 10 (4), 639-49. https://doi.org/10.1016/j.jobcr.2020.09.001.

Chen, B., Wu, W., Sun, W., Zhang, Q., Yan, F., \& Xiao, Y. (2014). RANKL expression in periodontal disease: where does RANKL come from?.BioMedresearchinternational, 2014, 731039. https://doi.org/10.1155/2014/731039.

Dengizek E., Serkan D., Abubekir E., Aysun Bay K., Onder O., \& Arife C. (2019). Evaluating clinical and laboratory effects of ozone in non-surgical periodontal treatment: a randomized controlled trial. Journal of Applied Oral Science, 27, e20180108.http://dx.doi.org/10.1590/1678-7757-2018-0108.

Ferreira, M. J. F., Marques, T. P., Nogueira, L. M., Pimenta, Y. S., Carlos, A. M., \& Nascimento, J. R., (2020). The use of ozonized oil in the healing process after dental implant surgery: literature review. Brazilian Journal of Development, 6 (11), 93559- 67. https://doi.org/10.34117/bjdv6n11-682

Isler, S. C, Unsal, B., Soysal, F., Ozcan, G., Peker, E., \& Karaca, I. R. (2018). The effects of ozone therapy as an adjunct to the surgical treatment of periimplantitis. Journal of Periodontal \& Implant Science, 48 (3), 136-51. https://doi.org/10.5051/jpis.2018.48.3.136. 
Leewananthawet, A., Arakawa, S., Okano, T., Kinoshita, R. D., Ashida, H., Izumi, Y., \& Suzuki, T. (2019). Ozone ultrafine bubble water induces the cellular signaling involved in oxidative stress responses in human periodontal ligament fibroblasts. Science and Technology of Advanced Materials, 20(1), 589-98. https://doi.org/10.1080/14686996.2019.1614980.

Makeeva, M. K., Daurova, F. Y., Byakova, S. F., \& Turkina, A. Y. (2020). Treatment of an endo-perio lesion with ozone gas in a patient with aggressive periodontitis: a clinical case report and literature review. Clinical, Cosmetic and Investigational Dentistry, 12, 447-64.

http://doi.org/10.2147/CCIDE.S267933.

Moraschini, V., Kischinhevsky, I. C., Calasans-Maia, M. D., Shibli, J. A., Sartoretto, S. C., Figueredo, C. M., \& Granjeiro, J. M. (2020). Ineffectiveness of ozone therapy in nonsurgical periodontal treatment: a systematic review and metaanalysis of randomized clinical trials. Clinical Oral Investigations, $24,1877-$ 88. https://doi.org/10.1007/s00784-020-03289-2.

Naik S.V., Rajeshwari K., Kohli S., Zohabhasan S., \& Bhatia S. (2016). Ozone - a biological therapy in dentistry: reality or myth?. The Open Dentistry Journal, 10 (1),196-206. DOI: 10.2174/1874210601610010196.

Nicolini, A. C., Rotta, I. S., Langa, G. P., Friedrich, S. A., Arroyo-Bonilla, D. A., Wagner, M. C., Weidlich, P., Rosing, C. K., \& Cavagni, J. (2020). Efficacy of ozonated water mouthwash on early plaque formation and gingival inflammation: a randomized controlled crossover clinical trial. Clinical Oral Investigations, 25, 1337- 44. https://doi.org/10.1007/s00784-020-03441-y.

Pietrocola, G., Ceci, M., Preda, F., Poggio, C., \& Colombo, M. (2018). Evaluation of the antibacterial activity of a new ozonized olive oil against oral and periodontal pathogens. Journal of Clinical and Experimental Dentistry, 10 (11), 1103-8. DOI: 10.4317/jced.54929.

Rapone, B., Ferrara, E., Corsalini, M., Converti, I., Grassi, F. R., \& Santacroce, L. (2020) The effect of gaseous ozone therapy in conjunction with periodontal treatment on glycated hemoglobin level in Subjects with Type 2 Diabetes Mellitus: An Unmasked Randomized Controlled Trial. International Journal of Environmental Research and Public Health, 17(15), 5467-78. https://doi.org/10.3390/ijerph17155467.

Roman-Torres, C. V., Bryington, M. S., Kussaba, S. T., Pimentel, A. C., Jimbo, R., \& Cortelli, J. R. (2018). Comparison of full-mouth scaling and quadrant wise scaling in the treatment of adult chronic periodontitis. Brazilian Denalt Journal, 29 (3), 296-300. http://dx.doi.org/10.1590/0103-6440201801715.

Saglam, E., Alinca, S. B., Celik, T. Z., Hacisalihoglu, U. P., \& Dogan, M. A., (2020). Evaluation of the effect of topical and systemic ozone application in periodontitis: an experimental study in rats. Journal of Applied Oral Science, 28, e20190140.http://dx.doi.org/10.1590/1678-7757-2019-0140.

Silva C.A., Pereira T.S., Quirino E.C., Ibiapina I.M., \& Fernandes A.U. (2021). Análise da eficácia da ozônioterapia no tratamento da peri-implantite: uma revisão de escopo. Research, Society and Development, 10 (1), e30210111465. http://dx.doi.org/10.33448/rsd-v10i1.11465

Silva, C. B., Paschoalotto, I. G., Dalto, B. L., Paschoalotto, I. G., Brancini, M. L., \& Alberghini, J. F. (2020). Ozone therapy in dentistry: review of major scientific considerations. International Journal of Development Research, 10 (04), 35060-3.

Suh, Y., Patel, S., Re, K., Gandhi, J., Joshi, G., Smith, N. L., \& Khan, S. A. (2019). Clinical utility of ozone therapy in dental and oral medicine. Medical Gas Research, 9 (3),163-7. DOI: 10.4103/2045-9912.266997.

Tasdemir, Z., Alkan, B. A., \& Albayrak, H., (2016). The effects of ozone therapy on the early healing period of de-epithelialized gingival grafts: a randomized placebo-controlled clinical trial. Journal of Periodontology, 87, 663-671. https://doi.org/10.1902/jop.2016.150217.

Tasdemir, Z., Oskaybas, M. N., Alkan, A. B., \& Cakmak, O., (2019). The effects of ozone therapy on periodontal therapy: A randomized placebo controlled clinical Trial. Oral Diseases, 25, 1195-202. https://doi.org/10.1111/odi.13060.

Uslu, M. O., \& Akgul, S., (2020). Evaluation of the effects of photobiomodulation therapy and ozone applications after gingivectomy and gingivoplasty on postoperative pain and patients' oral health-related quality of life. Lasers in Medical Science, 35, 1637-47. https://doi.org/10.1007/s10103-020-03037-8.

Walsh, N. C., Alexander, K. A., Manning, C. A., Karmakar, S., Wang, J. F., Weyand, C. M., Pettit, A. R., \& Gravallese, E. M., (2013). Activated human T cells express alternative mRNA transcripts encoding a secreted form of RANKL. Genes \& Immunity, 14 (4), 336-45. 